\title{
Tovomita acutiflora Barros et. G. Mariz espécie nova do Amazonas. Brasil
}

\author{
Maria Silveira de Barros (') \\ Geraldo Mariz ( $\left.{ }^{2}\right)$
}

\section{Resumo}

Tomovita acutiflora Barros et G. Mariz é proposta como uma nova espécie do gênero Tomovita Aublet. Foi coletada no Estado do Amazonas (Brasil) e enquadra-se na Secção Eutovomita Engler, Subsecção Clusiifoliae Vesque.

\section{INTRODUÇÃo}

Em continuação aos estudos do gênero Tovomita Aublet (Gutifferae) (Mariz, 1974a, 1974b), apresentamos a descrição de uma nova espécie do gênero, coletada no Estado do Amazonas, na mata das margens do Igarapé da Cachoeira Alta do Tarumã, em 06/06/1955 por Chagas, e cujo material se encontra depositado no Herbário do Instituto Nacional de Pesquisas da Amazônia (INPA) e Instituto Agronômido do Norte (IAN). Pela inflorescência terminal em ramos jovens se enquadra na secção Eutovomita Engler e por ter folhas com nervuras laterais numerosas, pouco ou não arqueadas perto da margem, bem como nervura marginal não confluente, se enquadra na subsecção Clusiifoliae Vesque.

\section{DiAgNose}

Planta Tovomita tenuifloris Benth affinis sed dimensionibus foli minoribus, dispositionibus nervi primarii et alabastro maiori differt.

Arbor $10 \mathrm{~m}$. Folia oblongo-elliptica. Petioli an $10 \mathrm{~mm}$ longi. Lamina ochracea (sicca), chartacea, oblongo-elliptica, basi et apice attenuata, apice leviter acuminata; $8-12 \mathrm{~cm}$ longa $x$ 3-4 $\mathrm{cm}$ lata, nervi numerosi (20-30) paraleli recti vel leviter arcuati, ad marginem irregulares.
Inflorescentia masculina terminalis, multiflora; pedunculus primarius $8 \mathrm{~mm}$ longus; pedunculi secundarius. 3-5 furcati, tuciarius. 2-3 furcati. Pedunculi secundarii $3-4 \mathrm{~mm}$ longi, bracteolis duabus $2-3 \mathrm{~mm}$ longis et $1-2 \mathrm{~mm}$ basi latis, instructi. Alabastra conica, angusta cuspidata $12-13 \mathrm{~mm}$ longa et $3-4 \mathrm{~mm}$ in basi lata.

Flores masculini duo sepalis triangularibus ad $12 \mathrm{~mm}$ longis, $3 \mathrm{~mm}$ latis, petala quatuor opposita, alba (seg. Chagas) $12-13 \mathrm{~mm}$ longa Stamina 30-40 basi lati interdum unita in disco plano inserta, filamenta linearia $10 \mathrm{~mm}$ longa, antherae parvae, apicales, bithece, rima deiscente. Pistillum nullum ne rudimentale guidem

Flores geminei et fructus ignoti.

Próxima de Tovomita tenuiflora Benth, difere dela por ter folhas menores, nervuras secundárias estruturalmente diferentes e botões maiores.

Arvore de $10 \mathrm{~m}$ de altura. Folhas oblongoelíticas, cartáceas, $8-12 \mathrm{~cm}$ de comp. x $3-4 \mathrm{~cm}$ de larg., ápice e base estreitando-se suavemente, ápice suavemente acuminado; nervuras secundárias numerosas (20-30) paralelas, retas ou levemente arqueadas para o ápice, irregulares nas margens.

inflorescência masculina, terminal multiflora. Eixo primário da tlor até $8 \mathrm{~mm}$ de comp. dividincio-se em 3-5 secundários e 2-3 terciários. O's pedúnculos secundários e terciários têm 3-4 mm de comp., 2 bractéolas triangulares agudas, com $2.3 \mathrm{~mm}$ de comp. $\times 1.2 \mathrm{~mm}$ de larg. na base. Botões estreitos, cônicos, ápice em cúspide, com 12-13 mm de comp. x 3-4 mm larg. na base; flores masculinas com 2 sépalas triangulares, cerca de $12 \mathrm{~mm}$ comp. $\times 3 \mathrm{~mm}$ de larg. 4 pétalas opostas, cruzadas, brancas (seg. Chagas) $12-13 \mathrm{~mm}$ de comp. Estames $30-40$

(1) - Bolsista do Conselho Nacional de Desenvolvimento Cientifico e Tecnológico (CNPq).

(2) - Universidade Federal de Pernambuco, Recife. 
dispostos sobre eixo plano algumas vezes concrescidos na base, filetes lineares, $10 \mathrm{~mm}$ de comp. Anteras pequenas, apicais, bitecas, deiscência rimosa. Ausência de rudimento de pistilo. (Fig. 1).

Flores femininas e frutos desconhecidos.

Habitat: terra firme, mata virgem.

Nome vulgar: Sapateiro.

$\mathrm{O}$ epíteto refere-se à forma do botão. TIPO. J. Chagas s.n. Brasil. Amazonas. Manaus. Margem do igarapé da Cachoeira Alta do Tarumã. Árvore de $10 \mathrm{~m}$; látex amarelo; flores alvas. Junho 1955 (holótipo: IAN 92095; isótipo: INPA).

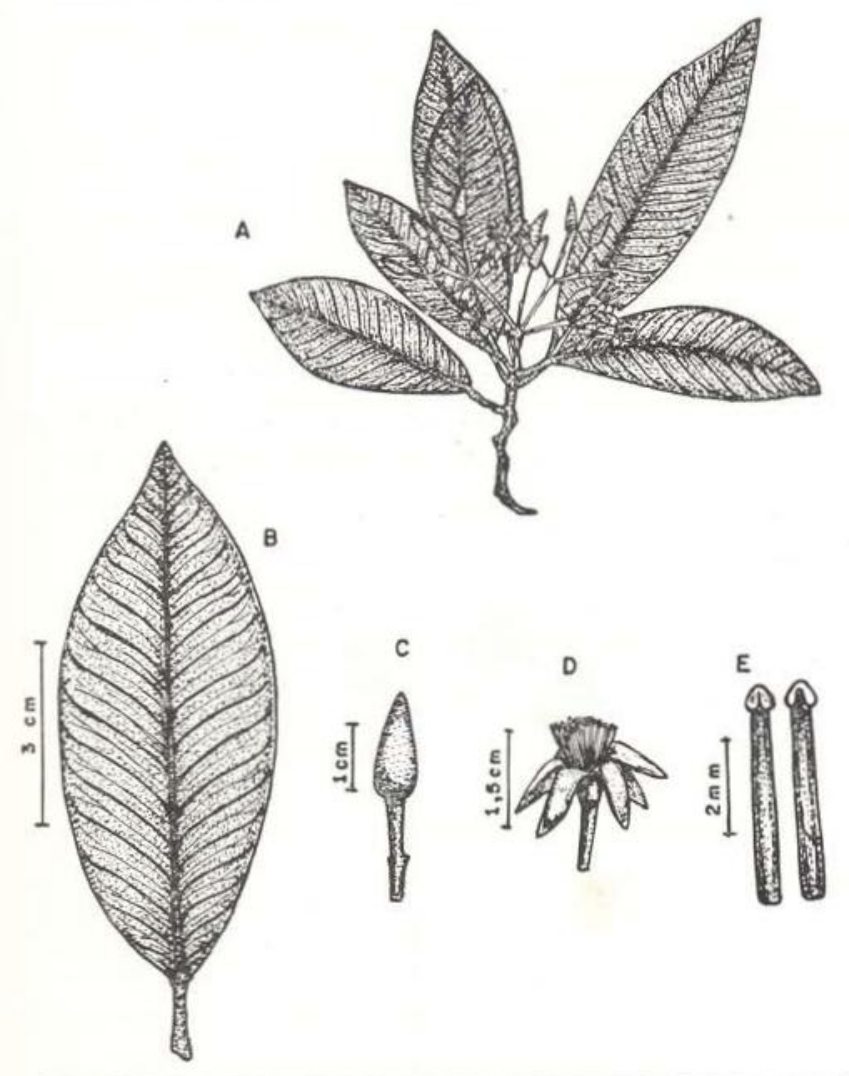

Fig. 1 - Tovomita acutiflora Barros et G. Mariz nov. sp. A - Ramo florido; B - Folha; C - Botão floral; D - Flor masculina; E - Estames.

\section{DISCUSSÃo}

Espécie semelhante a Tovomita tenuiflora Benth., da qual difere pelas folhas menores e mais estreitas, pelas nervuras secundárias irregularmente dispostas nas margens, pelos botões florais maiores e estames mais longos. As duas espécies parecem constituir uma linha evolutiva comum, pelo tipo de botão floral que as destaca das outras espécies da subsecção.

\section{Agradecimentos}

Agradecemos ao Pesquisador João Murça Pires, Chefe da Divisão de Botânica do Museu Paraense Emílio Goeldi (MG), pelo empréstimo do material botânico que serviu de base para este trabalho. Ao Prof. Dárdano Andrade Lima (in memória) pela sugestão do epíteto. Ao Prof. Pe. Aloysio Sehnem (in memória) pela gentileza da diagnose latina. À desenhista Eunice Montenegro pela ilustração. Ao ConseIho Nacional de Desenvolvimento Científico e Tecnológico $(\mathrm{CNPq})$. Ao laboratório de Botânica do Departamento de Biologia Especial da Universidade Federal de Pernambuco, pela permissão do uso de suas dependências.

\section{SUMMARY}

A new species belonging to subsecction Clusiifoliae Vesque, section Eutovomita Engler from Amazonas forest is described.

\section{REFERENCIAS BIBLIOGRÁFICAS}

MARIZ, G.

1974a- Tow new species of Tovomita Aublet (Guttiferae) from northeastern Brasil. Bull. Tor. Bot. Club, 101 (6): 367-371.

1974b- Guttiferae of Pernambuco (Brasil) Candollea, 29 7-11. Suisse.

(Aceito para publicaçăo em 18/05/82) 